\title{
Pattern of cerebral palsy in Mosul
}

\author{
Nada A.A. Al-Ali
}

Department of Pediatrics, College of Medicine, University of Mosul.

(Ann. Coll. Med. Mosul 2007; 33 (1\&2):15-19)

Received: $27^{\text {th }}$ Nov, 2005; Accepted: $9^{\text {th }}$ Jul, 2007

\section{ABSTRACT}

Objective: To examine the possible etiological factors, the clinical types, and the consequences of cerebral palsy in Mosul.

Methods: This prospective descriptive (case series study) took place in children's teaching hospitals Mosul. All children diagnosed as cerebral palsy between March 2000 and March 2005 were recruited for this study. Children without a clear diagnosis and those below the age of 12 months were excluded. Thus 306 Patients were recruited prospectively from those attending the inpatients and outpatients clinics of children's teaching hospitals in Mosul.

The caretakers of children were asked to fill in questionnaire. The patients were examined and classified. They were also assessed by an ophthalmologist and an audiologist; computerized tomography of the brain and EEG were performed when appropriate.

Results: There were 306 patients; 184 were females and I22were males. The female to male ratio was 1.5:1. Birth asphyxia accounted for $118(38.6 \%)$ of cases. Low birth weight accounted for $70(22.9 \%)$ of cases. The etiology was undetermined in 66 (21.4\%). Neonatal jaundice: 32 $(10.5 \%)$, meningoencephalitis:16(5.2\%), and brain malformations in $4(1.3 \%)$, spastic cerebral palsy was found in 244(79.7\%) of the clinical typing, psychomotor delay was present in 96 $(31.4 \%)$ and epilepsy was reported in 114 (37.3\%). Ocular problems were reported in 152 (49.7\%); speech problems were reported in 108 (35.3\%); and hearing problems were reported in $8(2.0 \%)$.

Conclusion: The etiological factors of cerebral palsy are sometimes preventable in our region. Improvement in antenatal, natal, and perinatal care is essential in the reduction of the incidence of cerebral palsy.

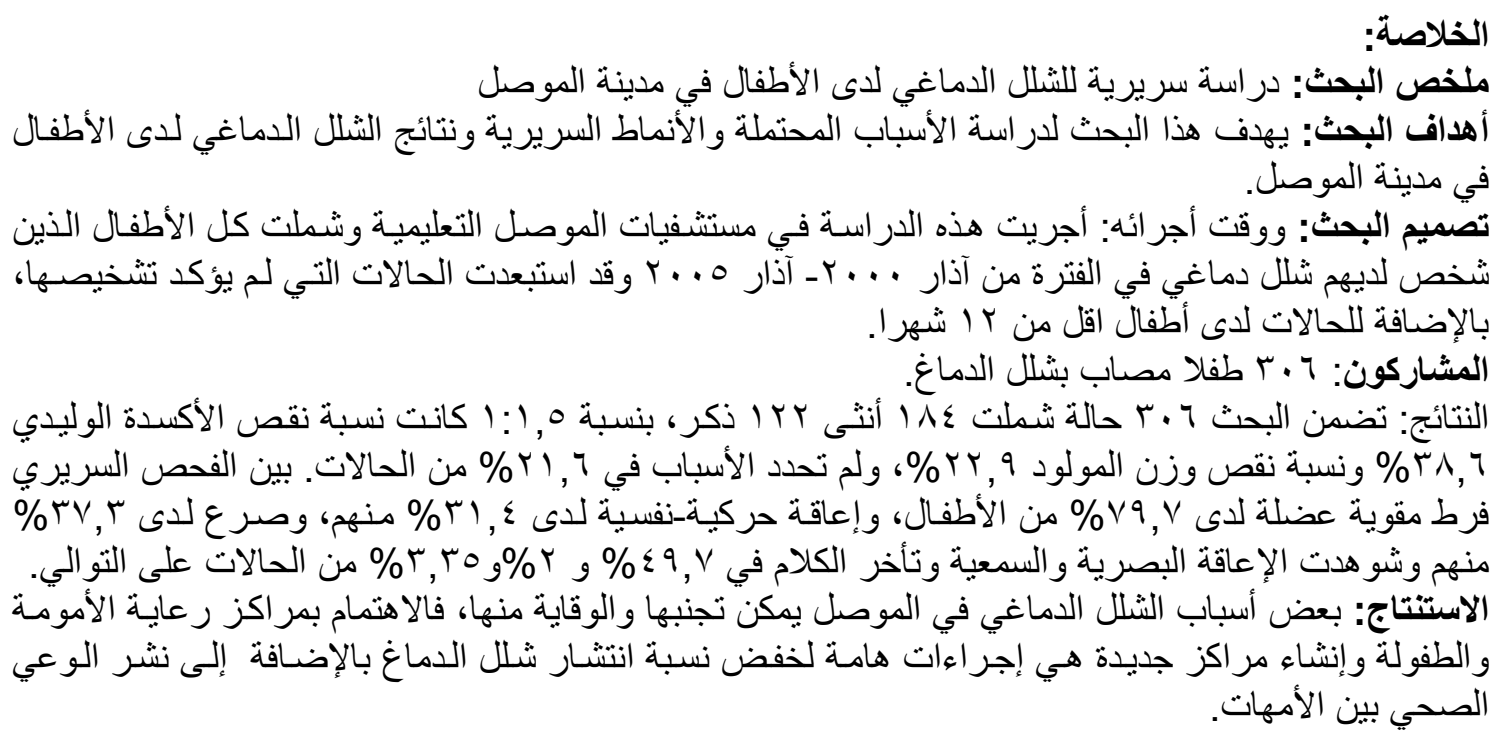


C erebral palsy (CP) is a form of static encephalopathy with impairment of motor function and posture. Basically, it is a non-episodic nonprogressive disorder that begins at birth or in early infancy. Cases of CP vary widely in their causes, manifestation, and prognosis. It is the leading cause of crippling handicaps in children and is often associated with epilepsy and abnormalities of speech, vision, and intellect ${ }^{(1)}$. Hansen ${ }^{(2)}$ reported an incidence of approximately 2 per 1000 in developed countries ${ }^{(3)}$ Many patients with the diagnosis of $\mathrm{CP}$ have normal or above average intelligence ${ }^{(4)}$. Expression of intellectual capacity may be limited by impairment in communication due to oromotor, fine motor, and gross motor difficulties. Without appropriate compensation, these difficulties have the potential to impair the ability to fully integrate academically and socially ${ }^{(5)}$. Complications associated with CP include cognitive difficulties, GI dysfunction, dental caries, sensory deficits, and a seizure disorder. A greater understanding of $\mathrm{CP}$ and the realization that patients with $\mathrm{CP}$ have significant potential to be unmasked allows medical professionals to approach $\mathrm{CP}$ in a multidisciplinary manner to maximize rehabilitative efforts ${ }^{(6)}$. The objective of the study was to determine etiological factors, clinical presentation, and associated consequences. The frequency of hospitalized cases with motor and mental handicaps raised our awareness of the need for this study.

\section{Patients and methods:}

This is a descriptive, epidemiological, hospital-based study. Patients were recruited prospectively from those attending the inpatient and outpatient clinics of the Children Teaching Hospitals in Mosul.

There were 306 children enrolled in the study. Those without a definitive diagnosis and patients under the age of 12 months in whom clear signs of CP might not have become manifest, e.g. spasticity, were excluded $^{(3)}$. The study was carried out between March 2000 and March 2005 .The caretakers of children were asked to fill in a questionnaire that included demographic data and medical history like age, sex, gestational age, age of the mother at birth, educational state, antenatal care, associated conditions like asphyxia, neonatal jaundice.. ect. The patients were examined and classified according to the Copenhagen Classification $^{(7)}$. They were also assessed clinically by an ophthalmologist, and audiolgist. Computerized tomographic brain scan and electroencephalography were performed for some of them when indicated.

\section{Results}

Of the 306 children with CP, 184(60.1\%) were females, and $122(39.9 \%)$ were males, giving a female to male ratio of $1.5: 1$. (table1).

Most of the children 214 (69.9\%) were born at home. and the rest were born in hospitals.

Four cases were older than 10 years and $258(84.3 \%)$ were less than 5 years. There were 52 preterm births and the remaining $258(83 \%)$ were term. Initiation of respiration was delayed with obvious pallor or cyanosis in 118 cases $(38.6 \%)$.

Demographic information about the mothers is shown in Table 2. Sixteen (5.2\%) were under the age of 16 at the time of childbirth. The majority were between 17-35 of age, forty-six $(15 \%)$ were illiterate. Ninetyfour $(30.7 \%)$ received no prenatal care. Seventy-four $(24.5 \%)$ had irregular visits to antenatal clinics. The majority 214 (69.9\%), lived in rural or semi-rural areas.

Some associated etiological factors are shown in Table 3. Birth asphyxia was reported in 118 cases $(38.6 \%)$. Sixteen $(5.2 \%)$ had a history of meningoencephalitis. The etiology was uncertain in $66(21.7 \%)$ of the cases.

The pattern of neurological deficit is shown in Table 4.Spastic CP was the most common type occurring in 244 of the 306 cases $(79.7 \%)$. Atonic and mixed varieties of CP were reported in $32(10.5 \%)$ and $22(7.2 \%)$ of the cases respectively.

Delay in achieving developmental milestones at the appropriate time associated with behavioral disorders was reported in 96(31.4\%). Recurrent seizures were present in 114 (37.3\%). Variable ocular problems were detected in 152(49.7\%) of the patients. Strabismus was the most common ocular complication occurring in 88 $(58.0 \%)$, and optic atrophy was the least common occurring in $8(5.3 \%)$. Sixty-two $(20.3 \%)$ had musculoskeletal complications, mainly tendon contractures, as shown in Table 5. 


\begin{tabular}{|c|c|c|}
\hline Condition & Number & Percentage \\
\hline Criteria & Number & percentage \\
\hline $\begin{array}{c}\text { Sex } \\
\text { Male } \\
\text { Female } \\
\end{array}$ & $\begin{array}{l}122 \\
184\end{array}$ & $\begin{array}{l}39.9 \\
60.1\end{array}$ \\
\hline $\begin{array}{l}\text { Age group } \\
1-5 \text { years } \\
>5 \text { years }\end{array}$ & $\begin{array}{c}258 \\
48\end{array}$ & $\begin{array}{l}84.3 \\
15.7\end{array}$ \\
\hline $\begin{array}{c}\text { Gestational } \\
\text { Term } \\
\text { Preterm } \\
\end{array}$ & $\begin{array}{c}254 \\
52 \\
\end{array}$ & $\begin{array}{l}83 \\
17 \\
\end{array}$ \\
\hline $\begin{array}{l}\text { Initiation of respiration } \\
\text { Immediate } \\
\text { Delayed }\end{array}$ & $\begin{array}{l}188 \\
118\end{array}$ & $\begin{array}{l}61.4 \\
38.6\end{array}$ \\
\hline
\end{tabular}

Table 2.Demographic information about mothers $(n=306)$

\begin{tabular}{|c|c|c|}
\hline Criteria & Number & Percentage \\
\hline Age at childbirth (years) & & \\
$\leq 16$ & 16 & 5.2 \\
$17-35$ & 252 & 82.4 \\
$>35$ & 38 & 12.4 \\
\hline Education & & \\
Illiterate & 46 & 15.0 \\
Primary school & 154 & 50.3 \\
Secondary school & 84 & 27.5 \\
University & 22 & 7.20 \\
\hline Rural & 214 & $69.9 \%$ \\
urban & 92 & $30.1 \%$ \\
\hline Antenatal care & 94 & 30.7 \\
None & 74 & 24.2 \\
Irregular & 138 & 45.1 \\
Regular & &
\end{tabular}

Table 3.Etiological Conditions associated with $\mathrm{CP}(\mathrm{n}=306)$

\begin{tabular}{|c|c|c|}
\hline Condition & Number & Percentage \\
\hline Asphyxia & 118 & 38.6 \\
\hline Low birth weight & 70 & 22.9 \\
\hline Meningoencephalitis & 16 & 5.2 \\
\hline Neonatal jaundice & 32 & 10.5 \\
\hline Brain malformation & 4 & 1.3 \\
\hline Unknown & 66 & 21.7 \\
\hline
\end{tabular}

Table 4. Clinical classification of CP $(n=306)$

\begin{tabular}{|c|c|c|}
\hline Clinical type & Number & Percentage \\
\hline $\begin{array}{l}\text {-Quadriplegia } \\
\text {-Diplegia } \\
\text {-Hemiplegia }\end{array}$ & $\begin{array}{c}244 \\
\\
102 \\
90 \\
52 \\
\end{array}$ & $\begin{array}{c}79.7 \\
\\
41.8 \\
36.9 \\
21.3 \\
\end{array}$ \\
\hline Atonic & 32 & 10.5 \\
\hline Extrapyramidal & 4 & 1.3 \\
\hline Ataxic & 4 & 1.3 \\
\hline Mixed & 22 & 7.2 \\
\hline
\end{tabular}




\begin{tabular}{|c|c|c|}
\hline \multicolumn{2}{|c|}{ 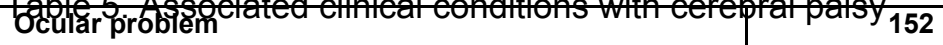 } & 49.7 \\
\hline $\begin{array}{l}\text {-Strabismus } \\
\text {-Nystagmus }\end{array}$ & $\begin{array}{l}88 \\
22\end{array}$ & $\begin{array}{l}58.0 \\
14.4\end{array}$ \\
\hline $\begin{array}{l}\text {-Optic Atrophy } \\
\text {-Mixed }\end{array}$ & $\begin{array}{r}8.0 \\
34 \\
\end{array}$ & $\begin{array}{l}5.3 \\
22.3 \\
\end{array}$ \\
\hline Epilepsy & 114 & 37.3 \\
\hline Speech problems & 108 & 35.3 \\
\hline Psychomotor delay & 96 & 31.4 \\
\hline Feeding problem & 80 & 26.1 \\
\hline Orthopedic complication & 62 & 20.3 \\
\hline -Muscle/tendon contracture & 54 & 87.1 \\
\hline -Hip dislocatio & 2.0 & 3.3 \\
\hline -Scoliosis & 6.0 & 9.6 \\
\hline Hearing & 8.0 & 2.0 \\
\hline
\end{tabular}

\section{Discussion:}

The study analyzed 306 children with cerebral palsy. There were more females with a ratio of $1.5: 1$, this is in contrast to published data from Nigeria and Saudia Arabia, both of which showed male predominance ${ }^{(7,8)}$. It is interesting to note that $69.9 \%$ were home births. Almost $50 \%$ of the mothers had attended an antenatal clinic on a regular basis. Trained midwives are available in most of Mosul at present time. The fact that very young mothers constituted a minority reflects the current trend away from early marriage in Mosul.

Cerebral palsy is not a static condition at the age of one year ${ }^{(9-10)}$. For this reason children under the age of 1 year were excluded from the study. Preterm infants, especially those who are small for gestational age, are at greater risk of developing $\mathrm{CP}^{(11-13)}$. The low rate obtained in this study, $52(17.0 \%)$ premature and $70(22.9 \%$ ) low birth weight (small for gestational age), can be attributed to the high perinatal, neonatal and early infancy mortality rates ${ }^{(14)}$. Most of these deaths were due to preventable causes ${ }^{(15-16)}$. Very few CP patients have survived beyond the 5th birth day. This is due to inappropriate medical care. Also there is lack of rehabilitation centers for handicapped children. The cerebral palsy rate in low birth weight infants is yet to be determined ${ }^{(17)}$.

Birth asphyxia, as indicated by delayed initiation of respiration, pallor, or cyanosis after a difficult birth, was reported in 118 $(38.6 \%)$ of cases. This is similar to the result published by Kurumuna in Dar Es Salaam ${ }^{(18)}$. This high rate reflects the lack of antenatal and perinatal care.
Neonatal jaundice and kernicterus are occasionally associated with $\mathrm{CP}^{(19)}$. In this study, a history of jaundice and exchange transfusion was reported in only $32(10.5 \%)$ of cases. In contrast is a report from West Africa where jaundice is a significant problem accounting for $88.0 \%$ of cases of cerebral palsy ${ }^{(20)}$.

As a group, children with $\mathrm{CP}$ have an unexpectedly higher incidence of congenital malformations. In one MRI study, ${ }^{(21)}$ one third of children with CP had cortical dysgenesis and neuronal migration. In this study, four children with severe mental retardation and microcephaly showed severe cortical atrophy on CT of the brain. Meningoencephalitis was reported in $16(5.2 \%)$ of cases. All of these cases were from rural or semi rural areas suggesting the possibility of delay in presentation for medical care. In $66(21.7 \%)$ of the patients, the cause of the CP was not determined. Lubis $^{(22)}$ reported a similar percentage in a retrospective study of $\mathrm{CP}$. Based on the predominant motor deficit, this study showed that $244(79.7 \%)$ of cases were spastic $\mathrm{CP}$, mainly quadriplegia, and diaplegia, $102(41.8 \%)$ and $90(36.9 \%)$ respectively. Similar data were reported from a number of countries ${ }^{(3)}$. In one study, spastic diplegia was detected in $53 \%$ and it was the commonest clinical type, regardless of birth weight and gestational age $\mathrm{e}^{(22)}$. Seizures were reported in $104(37.3 \%)$ of patients. Recurrent seizures were reported in one third of $\mathrm{CP}$ ith hemiplegia in another published study ${ }^{(23)}$. 


\section{Conclusion and recommendation}

We believe that the actual prevalence of $\mathrm{CP}$ is higher than that reported here. The designation of CP as an entity, regardless of underlying conditions, is valuable because medical care and rehabilitation requirements are similar. Rehabilitation centers should be established at the community level to offer integrated services to children with $\mathrm{CP}$ in order to reduce morbidity and mortality in this group, Cerebral palsy in Mosul is mostly secondary to preventable or remediable factors. More effort is needed to educate mothers about the value of antenatal and perinatal care. The cost of such programs is far less than those associated with treatment and rehabilitation.

\section{References}

1. Gaffney G, Flavell v, Johnson A, et al. Cerebral palsy and neonatal encephalopathy. Arch Dis Child 1994; 70:195.

2. Robinson MJ. Cerebral palsy in: Practical Pediatrics. Edinburgh: Churchill Livingstone: 1986. 374-81

3. Swaiman KF. Cerebral palsy in: Pediatric Neurology. Principles and Practice. edition. 1999. Mosby.

4. Ashwal S, Russman BS, Blasco PA, et al: Practice parameter: diagnostic assessment of the child with cerebral palsy: report of the Quality Standards Subcommittee of the American Academy of Neurology and the Practice Committee of the Child Neurology Society.

Neurology 2004; 62(6): 85 1-63.

5. Stevenson DK, Benitz WE, Sunshine P: Fetal and Neonatal Brain Injury Mechanisms, Management and the Risks of Practice. 3rd ed. Cambridge University Press; 2003

6. Volpe JJ: Neurology of the Newborn. 4th ed. WB Saunders; 2001: 4 ..

7. Christensen F, Meichior J. Cerebral palsy in a clinical neurological $\mathrm{s}$ Study. Clin Dev Med 1967; 25.

8. Taha SA, Mahdi AR, CP in Saudi Arabia: a clinical study of 102 cases. AnnTropPaediatr1984 3:155-8.
9. Forfar, J. and Arnel T. cerebral palsy in (text book of pediatrics) $3^{\text {rd }}$ Edit; London Churchill 1992 p:802-819.

10. Behrman RB, Kliegman RM, Arvin AM. Encephalopathies in: Nelson Textbook of Pediatrics, $15^{\text {th }}$ edition. Phiadelphia: W.S. Saunders. 1996.p: 1515-1517

11. Ford GW, Kitchen WH, Doyle LW, Richard AL, Kelly E. Changing diagnosis of cerebral palsy in very low birth weight children. Am J Perinatol 1990; 7:178-81.

12. Koeda T, Suganuma I, Kohuo Y,et al. MRI imaging of spastic diplegia. Comparative study between preterm and term infants. Neurology 1990; 32:187.

13. Nelson KB, Ellenberg JR. Predictors of low very low birth weight and the relation of these to cerebral palsy. JAMA 1985; $254: 1473$

14. UNICEF. The state of the world's children. Oxford University Press. 2000.

15. Taha ET, Gray HG, Abdel Wahab MM. Determinations of Neonatal Mortality in Central Sudan. Ann Trop Pediatr 1993; 13(4): 359-364

16. Taha ET, Gray HG. Malaria and perinatal mortality in central Sudan. Am J Epidemiol 1993; 138 (8): 563-8

17. Phroah POD, Cooke T, Coke, RWI, et al. Birth weight specific trends in cerebral palsy. Arch Dis child 1990; 65:602

18. Karumuna JM, Mayon CS. Cerebral palsy in Dar Es Salaam. Cent Aft J Med 1990; 36 (1):8-10.

19. Miller G, Clark CD. The cerebral palsy causes, consequences, and mangment. Bosten .Butterworth .Heinamann 1998

20. Laditan Aao, Effiong LE, Antio Al. Morbidity and mortality from exchange blood transfusion in neonatal jaundice. Nigerian Journal of Pediatrics 1975;2: 42-6

21. Volpe JI. Value of MRI in definition of the neuropathological cerebral palsy in vivo AJNR. Am J Neuroradiol 1992; 199; 13:79.

22. Lupis MU; Tjipta GD, Marbun MD, saing B. Cerebral palsy. Paediatr Indonesia 1990; 30 (3-4).

23. Aicadia J. Epilepsy in brain injured with cerebral .Dev med din Neurol 1990; 23:191 